\title{
Female-Female Social Relationships in Wild White-Faced Capuchin Monkeys, Cebus capucinus
}

\author{
SUSAN PERRY \\ Department of Anthropology, The University of Michigan, Ann Arbor, Michigan
}

A single social group of wild white-faced capuchin monkeys was studied for a period of 26 months at Lomas Barbudal Biological Reserve, Costa Rica. A total of $604 \mathrm{hr}$ of focal animal data was collected on six adult females in a group of 21 monkeys. Females could be ranked in a stable, linear dominance hierarchy. Adult females spent much more time in proximity to other adult females than to adult males. Females groomed other females twice as often as they groomed males, and about 55 times more often than males groomed males. Females tended to groom up the dominance hierarchy, and dyads with smaller rank distances groomed more often. Higher-ranking females nursed infants other than their own at lower rates than did lower-ranking females; however, females nursed infants of females ranked both above and below them. Although lower-ranking females were more likely than higher-ranking females to be the victims of aggression, higher-ranking females were not necessarily more aggressive than lower-ranking females. In $96 \%$ of female-female coalitions vs. a female, the victim was lower-ranking than both coalition partners; in the remaining $4 \%$, the victim was intermediate in rank between the two coalition partners. Higher-ranking female-female dyads formed coalitions more often than did lower-ranking dyads. Those female-female dyads that groomed more frequently also formed coalitions more frequently. The patterning of social interactions indicates that Cebus capucinus at Lomas Barbudal are female bonded. (1) 1996 Wiley-Liss, Inc.

\section{Key words: Cebus capucinus, female-female social relationships, coalitions, allonursing}

\section{INTRODUCTION}

Female-female relationships (particularly grooming, coalitionary support, agonism, dominance and dominance rank acquisition, and attraction to others' infants) have been studied extensively in catarrhine primates, but rarely in platyrrhines. Female-female relationships in capuchin monkeys (Cebus) should be of particular interest because capuchins, like most cercopithecine monkeys but unlike most platyrrhines, exhibit female philopatry [Robinson \& Janson, 1987],

Received for publication October 5, 1995; revision accepted April 8, 1996.

Address reprint requests to Dr. Susan Perry, Department of Anthropology, UCLA, 405 Hilgard Avenue, Los Angeles, CA 90095-1553. 


\section{8 / Perry}

which has been proposed to influence the quality of female-female relationships [Wrangham, 1980; van Schaik, 1989].

Fedigan [1993] found that among wild C. capucinus, (1) females interacted more frequently overall with other females than with males, (2) females had more affiliative interactions with females than with males, and (3) females could be ranked in a linear hierarchy (according to direction of supplantation, or to aggressive signals followed by submissive signals from the recipient). O'Brien [1993] reports for $C$. olivaceus females that grooming was preferentially directed down the dominance hierarchy, and that females with new infants (aged 1-2 months) were groomed more often than females without new infants. In one wild group of $C$. apella, the alpha female received nearly twice as much grooming as she directed [Robinson \& Janson, 1987]. Allonursing (females nursing other females' infants) may be considered an aspect of female-female relationships even though the interactions themselves are between immatures and adult females. O'Brien [1988] reported for $C$. olivaceus that, in 13 observations of allonursing in four adult female/juvenile dyads, the juvenile's rank was always higher than the nursing female's rank. O'Brien and Robinson [1991] did not find any influence of kinship or rank on rates of allonursing in adult female/infant dyads.

In this paper, I use data from wild Cebus capucinus to describe various facets of female-female social relationships: proximity, grooming, aggression, coalition formation, allomothering, and handsniffing. Female-female social relationships are compared to male-male and intersexual social relationships. Finally, I place these findings in the contexts of (1) recent discussions of the functions of grooming in platyrrhine and catarrhine primates [Dunbar, 1991, 1993; Snowdon, 1993; Glezer \& Kinzey, 1993] and (2) socioecological models of primate sociality [Wrangham, 1980; van Schaik, 1989].

\section{METHODS}

I studied a single social group of 21 wild white-faced capuchin monkeys (four adult males, six adult females, and 11 juveniles and infants) in the vicinity of Lomas Barbudal Biological Reserve, Guanacaste, Costa Rica. Lomas Barbudal is a highly seasonal tropical dry forest; the site is described in detail in Frankie et al. [1988]. I conducted a pilot study in May-August 1990, but the focal data analyzed here were collected during May 1991-May 1993. The monkeys were followed from dawn to dusk every day for up to 25 sequential days per month. The mean number of contact hours per month was 136 (range: 8-308; $\mathrm{SE}=17.4$ ). Adult monkeys and juveniles were easily identified by scars, hair color patterns, and facial contours. Infants were marked midway through the study (March 1992) by squirting them on their backs at a range of 3-10 m via syringe with hair lightener. Kinship relationships for adult females are not known.

Data were collected during 10 min continuous focal animal samples, in which all social behaviors and the identities of the interactants were recorded. Every 2.5 min, I did a scan sample in which I noted the identities of all monkeys in my view and recorded the proximity of each monkey to the focal animal. Three observers assisted in data collection. Data were collected in teams of two people per focal sample, to ensure accuracy in identification of individuals and behaviors. When the observers did not agree, the data were discarded. The analyses in this paper are based on $603.67 \mathrm{hr}$ of focal samples of females (and $364.5 \mathrm{hr}$ of samples on adult males for comparative purposes, collected via identical methods), collected during $3,800 \mathrm{hr}$ with the group. Approximately $39 \%$ of the contact hours occurred during the rainy season, and $61 \%$ in the dry season. However, about $29 \%$ of focal animal samples were collected during the rainy season and $71 \%$ during the dry season. 
TABLE I. Focal Data Collected on Adult Females

\begin{tabular}{lr}
\hline Female & Hours \\
\hline Abby & 110.83 \\
Squint & 111.00 \\
Nanny & 110.50 \\
Diablita & 48.00 \\
Wiggy & 113.50 \\
Tattle & 109.83 \\
\hline
\end{tabular}

Table I summarizes the amount of focal data collected on each female. Ad libitum data were collected on relatively rare social events such as aggression and sexual behavior. The subjects of the analyses in this paper were six adult females, one of whom matured to adulthood in October 1992, when she was first judged (by behavioral criteria) to be in estrus. Throughout the data tables in this paper, females are listed in order of dominance rank, from top to bottom or from left to right. Females are referred to by the first letter of their names in all tables.

A completely random order of focal subjects was not feasible due to the difficulty of locating any one particular monkey in dense vegetation at any given time. The task is made more difficult by the fact that capuchins often disperse widely while foraging and frequently become separated from the group. I completed focal animal samples of all females before beginning another round of samples; however, if I had good reason to believe that an individual was missing from the group, I eventually proceeded to the next round without sampling her. The next focal animal was always the first eligible monkey to be seen that had not interacted with the previous focal animal or been within one body length of her during the last 2.5 min of the previous sample.

\section{Behavioral Definitions}

Dominance was defined by the direction of dyadic avoidance and cowering. Aggressive behaviors were not used to define the dominance hierarchy, due to the coalitionary nature of most capuchin aggression.

"Aggression" included mild aggression (open-mouth threats, vocal threats, lunging) and severe aggression (chases, hitting, wrestling, biting). Mild and severe aggression were combined for all analyses, but similar patterns of aggression were obtained when mild and severe aggression were analyzed separately. Aggression scores were expressed as the proportion of a dyad's 10 min samples in which aggression occurred.

A "coalition" was defined as joint aggression by two or more individuals toward a third party. Coalitions sometimes consisted of two individuals chasing or directing open-mouth threat faces at a third individual. Commonly, the coalition partners threatened the victim while in physical contact with one another. They stood cheek-to-cheek, embraced, or did an "overlord" [Oppenheimer \& Oppenheimer, 1973], which was defined as two or more monkeys stacked on top of one another with their heads aligned, staring at and/or threatening a third individual. A "headflag" was defined as one monkey jerking its head toward a prospective coalition partner and then resuming a stare or threat toward its opponent; the headflag is the most common behavior used in coalition partner recruitment. A headflag in the absence of overt joint aggression was not scored as a coalition. The details of specific aggressive behaviors are defined in greater detail elsewhere [Oppenheimer, 1973; Perry, 1995]. 


\section{0 / Perry}

Coalition scores were calculated by dividing the number of $10 \mathrm{~min}$ samples in which a given dyad formed coalitions against a specific victim by the total number of samples in which that coalition-victim triad could have interacted (i.e., all focal animal samples collected during time periods in which all three members of the triad were residing in the group as adults). When more than two females formed a coalition, each dyad was scored separately. For example, if monkeys A, B, and C formed a coalition against monkey $D$ during a focal animal sample of $C$, I scored coalitions of $\mathrm{A}-\mathrm{C}$ and $\mathrm{B}-\mathrm{C}$ against $\mathrm{D}$. If the same three monkeys formed a coalition against $D$ during a focal animal sample of $D$, I scored coalitions of $A-B, A-C$, and $\mathrm{B}-\mathrm{C}$ against $\mathrm{D}$. For the analysis of association between support and grooming, "support" was scored only when the female was the first monkey to provide agonistic aid to the fighting female. In some cases, two females simultaneously initiated support, and both were scored as supporters. Often many monkeys participated in a coalition against the same victim. Individuals that provided agonistic aid later in the dispute were not scored as supporters of the female originally involved in the fight, because it was not clear whether the later participants were offering aid to the original female or to one of her supporters. In a few cases, it was impossible to determine which of the two females was the initiator of the fight and which was the supporter, because they began threatening their victim simultaneously. In these cases, each female was given half-credit for supporting the other for that fight.

"Handsniffing" was scored when two females covered each other's noses with one hand or inserted their own fingers in their partner's nostrils, and both females deeply inhaled for a period of up to several minutes. Occasionally handsniffing was unidirectional, but it was typically mutual.

"Allonursing" was defined as an infant nursing from a female other than its own mother. Females were often observed to nurse, carry, and groom one another's infants. It seemed that the period of 3-6 months of age-the period during which infants were first beginning to explore extensively away from their mothers, yet remained dependent on milk for most of their nutritional needs-was the period during which the most allonursing occurred. During this period, observers frequently observed two separate infants nurse in quick succession from the same female, or two infants nursing simultaneously from the same female. Unfortunately, we could not reliably identify infants individually until March 1992, when we marked them with hair dye. Therefore, Eldritch (born to Tattle April 7, 1992) was the only infant who was individually recognizable for the entirety of the 3-6 month phase. All allonursing rates are based on adult female focal data collected after March 29, 1992, when all infants but Eldritch were over 10 months of age.

Proximity scores were calculated in the following manner. For each femalefemale dyad, I tallied the number of times, during the final scan sample of each 10 min sample of either female, that the females were within $0-1$ body lengths, 1-5 body lengths, and 5-10 body lengths of one another. A body length was defined as the length, from nose to tailbase, of an adult male capuchin monkey. Because a single score is easier to use for comparative purposes than three separate scores, I combined these scores in a single composite proximity score as follows. I multiplied these three numbers by weighting factors, such that the closer proximity categories were weighted more heavily, to reflect the lower probability of a female ending up in a smaller sphere surrounding the focal female by chance. The weighting factors were determined in the following way. Imagine three concentric spheres, with the focal animal at the center. The inner sphere has radius one, the second largest sphere has radius five, and the outer sphere has radius 10 . The weighcing value for the number of samples in which the animals of a dyad are within one 
length of one another is the reciprocal of the volume of a sphere of radius one. The weighting value for the 1-5 body length category is the reciprocal of the difference between the volume of a sphere of radius five and the volume of a sphere of radius one. The weighting value for the 5-10 category is the reciprocal of the difference between the volumes of spheres of radius 10 and radius five. Thus, the equation for calculating the proximity score is:

$$
\text { proximity score }=1,000(0.239 \mathrm{a}+0.0019 \mathrm{~b}+0.0003 \mathrm{c})
$$

where " $a$ " is the proportion of samples in which the members of the dyad are within one length of one another, " $b$ " is the proportion of samples in which the two animals are within 1-5 lengths of one another, and " $c$ " is the proportion of samples in which the animals are within 5-10 lengths of one another. The sum of the three weighted values is multiplied by the arbitrary value of 1,000 simply to make the proximity scores more readable; otherwise, they would all be small fractions. The higher the proximity score, the more time the animals spent in close proximity.

Grooming was defined as one monkey manipulating the skin or hair of another monkey, either with the hands or with the mouth. On December 30, 1991, the method of recording grooming was changed from merely recording grooming as an event to recording it as a state, with duration recorded in seconds. Therefore, the grooming data presented throughout the paper are based only on data between December 30, 1991, and May 8, 1993.

\section{Statistical Analysis}

In some cases, data were analyzed in two different ways: first, using traditional rank correlation techniques (Kendall's tau) in which dyads are treated as separate data points, and second, using matrix correlation techniques, in which data are analyzed at the group level [e.g., Hemelrijk, 1990a,b]. The first method has the advantage of being easier to grasp intuitively, and such statistical methods have been widely used to address similar questions in primate behavior. However, the second method is superior because it controls for individual differences in behavior (e.g., some females may be more avid groomers than others). Hemelrijk's [1990a,b] method computes correlations across dyads for each individual and sums the correlations for all individuals, thus circumventing the problem of lack of independence among dyads.

Throughout the paper, dominance rank was treated as an ordinal, rather than a nominal, variable. Whenever the dyad was the unit of analysis and comparisons were made between rank and the rate of a behavior that occurred between the members of the dyad, the terms "higher ranking" and "lower ranking" referred to the rank of one member of the dyad relative to the other member of the dyad. When the individual was the unit of analysis and rank was being related to a measure of social behavior, the terms "lower ranking" and "higher ranking" were used to indicate that the behavior occurred at higher rates in individuals ranked toward one end of the dominance hierarchy relative to individuals ranked toward the other end of the hierarchy.

In order to test Seyfarth's [1977] "attraction to rank" hypothesis, I created a hypothesis matrix (Table II) against which to compare the matrix of grooming rates (see Table V), using the program "MATSQUAR" [Hemelrijk, 1990a]. "MATSQUAR" calculates a measure of association between the grooming matrix and the hypothesis matrix, using the $K_{r}$ statistic. The $K_{r}$ statistic first calculates the Kendall rank correlations within rows (i.e., within individuals), and then combines these in an association measure; thus, it takes individual variation into 
TABLE II. Hypothesis Matrix for Testing the Attraction to Rank Hypothesis

\begin{tabular}{lllllll}
\hline & A & S & N & D & W & T \\
\hline A & X & 5 & 4 & 3 & 2 & 1 \\
S & 6 & X & 4 & 3 & 2 & 1 \\
N & 6 & 5 & X & 3 & 2 & 1 \\
D & 6 & 5 & 4 & X & 2 & 1 \\
W & 6 & 5 & 4 & 3 & X & 1 \\
T & 6 & 5 & 4 & 3 & 2 & X \\
\hline
\end{tabular}

account. "MATSQUAR" determines the level of statistical significance by randomly permuting the entries in one matrix while holding the values in the other matrix constant, to generate a sampling distribution. The rationale behind using this procedure is explained in detail in Hemelrijk [1990a]. The same hypothesis matrix was used to determine whether higher-ranking females were more likely than lower-ranking females to provide support against males and females. The $K_{r}$ statistic was used to compare the two matrices, and the probability level was based on 2,000 permutations. $P$ values are one tailed. To test whether there was an association between support and grooming, controlling for the effects of rank, I used Hemelrijk's program "MATSQP" [Hemelrijk, 1990b], which computes partial correlations for matrices. The rank matrix used to test the "attraction to rank" hypothesis (Table II) was used as the matrix held constant in determining partial correlations among grooming, support, and rank. A positive association between the rates of two types of social favors may or may not involve cognitive calculations of exchanges on the part of the animals; the association could be due to the effects of a third variable. Only experiments could determine whether an exchange of favors is taking place, but a finding that the two variables are not associated could falsify the hypothesis that exchange of favors is occurring (see Discussion).

\section{RESULTS}

\section{Dominance Hierarchy}

Females could be ranked in a linear hierarchy according to avoidance and cowering during focal samples (Table III). There were very few dyads in which avoids or cowers were observed in both directions. All entries above the diagonal in Table III were instances of probable triadic interactions, or cases in which the adolescent female Diablita was ascending the hierarchy. In one dyad, Wiggy/Tattle, no avoids or cowers were observed during focal animal samples, although Tattle was observed to behave submissively to Wiggy several times during ad libitum observations. Appleby's [1983] adaptation of Kendall's [1962] test of linearity revealed that the females' dominance relationships displayed transitivityi.e., the observed pattern of dominance relationships was consistent with a linear hierarchy to a greater extent than would be expected by chance ( $\mathrm{df}=30, x^{2}=51$, $P<0.05$ ).

\section{Proximity}

Adult females' proximity scores with other females were 11 times as high as males' proximity scores with other males, and 3.2 times as high as male-female proximity scores. Figure 1 shows the distribution of proximity scores by sex class of dyad: there is no overlap between the scores of male-male and female-female dyads. Proximity scores for most male-male and male-female dyads changed by an order of magnitude or more following a rank reversal between the alpha male and 
TABLE III. Avoidance and Cowering Within Adult Female Dyads

\begin{tabular}{lcccccc}
\hline & \multicolumn{6}{c}{ Recipient } \\
\cline { 2 - 7 } Actor & A & S & N & D & W & T \\
\hline A & - & 0 & 0 & 0 & 0 & 0 \\
S & 1 & - & 1 & 0 & 0 & 0 \\
N & 4 & 9 & - & 1 & 1 & 0 \\
D & 2 & 3 & 4 & - & 1 & 0 \\
W & 4 & 3 & 2 & 2 & - & 0 \\
T & 1 & 7 & 3 & 1 & 0 & - \\
\hline
\end{tabular}

a subordinate male in November 1992, during which time there was much tension in the males' relationships [Perry, 1995]. However, adult females' proximity scores with one another remained fairly stable over time. (Pre- and postreversal proximity scores were positively correlated: $\tau=0.449, \mathrm{n}=15$ dyads, $P=0.02$ ).

Table IV shows each female's proximity scores with other females, averaged across dyads. These scores did not vary greatly across individuals, except for Squint's scores and Tattle's scores. If proximity scores are good indicators of social bonds, then Squint, the beta female, had the strongest network of female social partners.

\section{Grooming}

When grooming rates were averaged across dyads for each individual, and then averaged across individuals for each sex class, females groomed other females at a rate of $11.53 \mathrm{sec} / \mathrm{hr}$, which was twice as often as females groomed males, 43-68 times as often as males groomed other males (depending on whether prereversal or postreversal data are used), and 144 times as often as males groomed females. Table $\mathrm{V}$ shows the rates of grooming for each female-female dyad between December 30, 1991, and the end of the study. Data from focal samples for both members of each dyad are included in these tables. Hemelrijk's [1990a] method, in which the grooming matrix was compared to a hypothesis matrix (Table II), showed a significant tendency for grooming to be directed disproportionately toward higher-ranking females $\left(K_{r}=22 ; 2,000\right.$ permutations; $\left.P_{r}=0.048\right)$. Use of a Wilcoxon matched pairs test to examine whether up-hierarchy grooming was more common than down-hierarchy grooming yielded a nonsignificant trend in the same direction $(\mathrm{n}=15$ dyads, $\mathrm{t}=35, P=0.15 ; \mathrm{X} \pm \mathrm{SD}=14.3 \pm 11.17 \mathrm{sec} / \mathrm{hr}$ up hierarchy; $\mathrm{X} \pm \mathrm{SD}=8.75 \pm 7.22 \mathrm{sec} / \mathrm{hr}$ down hierarchy). Rank was correlated with grooming such that higher-ranking individual females received higher rates of grooming (Kendall: $\tau=-0.83, \mathrm{n}=6$ individuals, $P=0.02$ ), but rank was unrelated to the amount of grooming directed (Kendall: $\tau=0.07, \mathrm{n}=6$ individuals, $P=0.8$ ).

Those dyads that had a smaller rank distance groomed more often overall $(\tau=$ $-0.50, \mathrm{n}=15$ dyads, $P=0.0097$ ). This result was stronger when only downhierarchy grooming was considered $(\tau=-0.54, \mathrm{n}=15$ dyads, $P=0.005)$ than when only up-hierarchy grooming was considered $(\tau=-0.37, \mathrm{n}=15$ dyads, $P=$ 0.054).

Because only one birth occurred during the period in which grooming durations were recorded, it is difficult to address the question of whether the presence of a new infant affects grooming rates, as predicted by Seyfarth's model. Tattle was groomed by females at a mean rate (averaged across females) of $2.3 \mathrm{sec} / \mathrm{hr}$ during 
174 / Perry

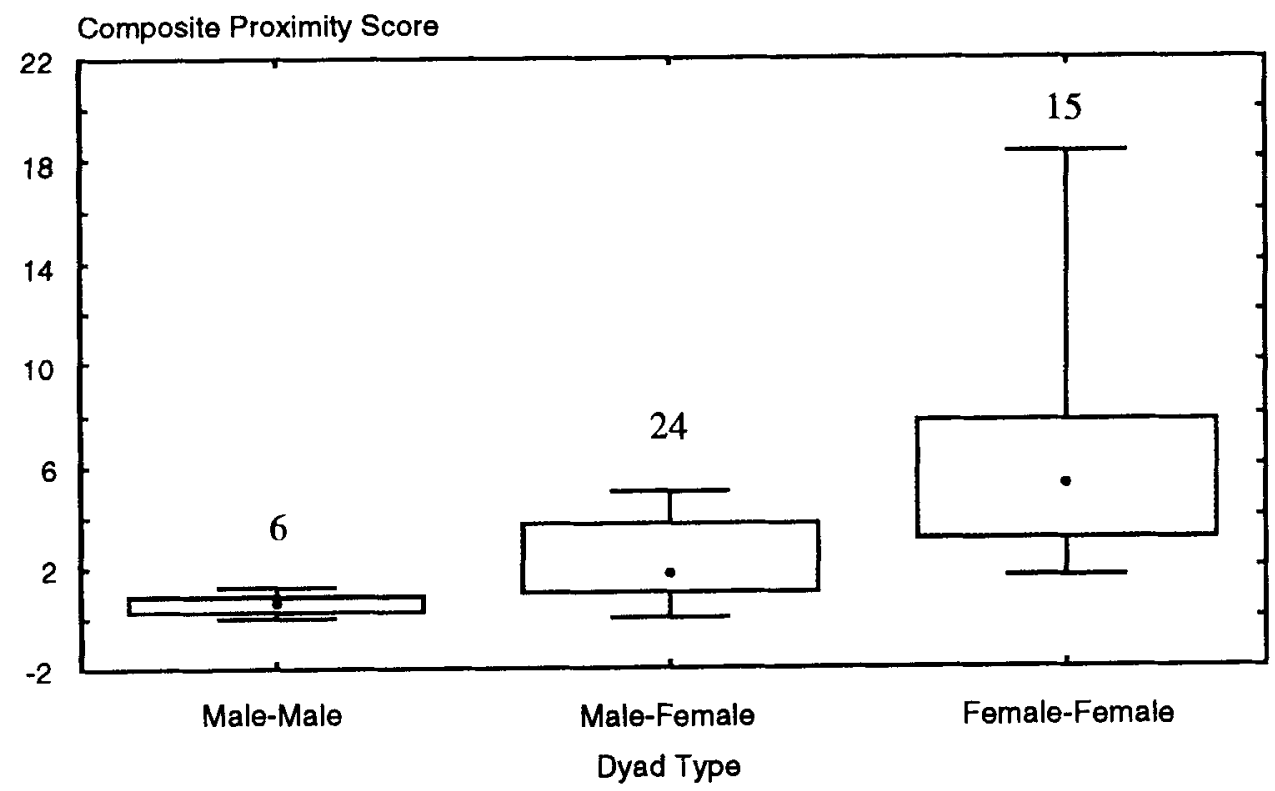

Fig. 1. Proximity scores, according to sex class of dyad. Boxes show the median and interquartile range, and whiskers show the total range of variation within each sex class of dyad.

TABLE IV. Females' Proximity Scores With Other

Females, Averaged Across Dyads; Females Are Listed in Order of Rank, From Highest to Lowest

\begin{tabular}{lc}
\hline Female & Proximity score \\
\hline Abby & 7.4 \\
Squint & 10.6 \\
Nanny & 6.5 \\
Diablita & 5.8 \\
Wiggy & 5.6 \\
Tattle & 2.9 \\
\hline
\end{tabular}

the 2 months prior to her infant's birth, compared to $22.4 \mathrm{sec} / \mathrm{hr}$ during the 2 months following her infant's birth.

Handsniffing was engaged in only by adult female-female dyads. Rates of grooming were positively correlated with rates of handsniffing (Kendall tau, $\tau=$ $0.499, \mathrm{n}=15$ dyads, $P=0.009$ ).

\section{Allomothering}

All adult females allonursed. Higher-ranking females allonursed at lower rates than did lower-ranking females $(\tau=0.95, \mathrm{n}=5, P=0.02)$, as shown in Figure 2. However, it appears that the rank of the infant's mother, relative to the rank of the allonursing female, is irrelevant (Fig. 3). Females frequently nursed infants of lower-ranking females. I compared the rates at which infants nursed from females who were higher ranking than their mothers to rates at which in- 
TABLE V. Rates of Female-Female Grooming, Seconds/Hour, Between $12 / 30 / 91$ and $5 / 8 / 93$

\begin{tabular}{lrrrrrrr}
\hline & \multicolumn{7}{c}{ Recipient } \\
\cline { 2 - 8 } Actor & $\mathrm{A}$ & $\mathrm{S}$ & $\mathrm{N}$ & $\mathrm{D}$ & $\mathrm{W}$ & $\mathrm{T}$ & Mean \\
\hline $\mathrm{A}$ & - & 5.8 & 3.5 & 2.1 & 2.3 & 0.04 & 2.7 \\
$\mathrm{~S}$ & 41.6 & - & 28.6 & 18.1 & 9.0 & 7.4 & 20.9 \\
$\mathrm{~N}$ & 10.3 & 25.5 & - & 9.6 & 9.9 & 4.3 & 11.9 \\
$\mathrm{D}$ & 23.3 & 9.3 & 10.5 & - & 13.4 & 6.9 & 12.7 \\
W & 21.2 & 15.2 & 14.6 & 25.1 & - & 10.4 & 17.3 \\
$\mathrm{~T}$ & 2.5 & 2.9 & 3.7 & 3.6 & 5.3 & - & 3.6 \\
Mean & 19.8 & 11.7 & 12.2 & 11.7 & 8.0 & 5.8 & 11.5 \\
\hline
\end{tabular}

fants nursed from females lower ranking than their mothers. Infants did not nurse preferentially from females lower ranking than their own mothers (Wilcoxon: $\mathbf{n}=$ 10 dyads, $\mathrm{X} \pm \mathrm{SD}_{\text {nursing from higher-ranked female }}=0.03 \pm 0.024$ bouts $/ \mathrm{hr}, \mathrm{X} \pm \mathrm{SD}_{\text {nursing }}$ from lower-ranked female $=0.04 \pm 0.038 ; \mathrm{T}=16, P=0.44$ ). Within each adult female dyad, I compared the rate at which the higher-ranking female nursed the lowerranking female's infant to the rate at which the lower-ranking female nursed the higher-ranking female's infant, to determine whether mothers might be engaging in reciprocal exchanges of allonursing services. No correlation was found (Kendall: $\tau=0.133, \mathrm{n}=10$ dyads, $P=0.59$ ). Allonursing was not associated with coalitional support; nor was it associated with grooming.

\section{Aggression}

Aggression was directed primarily down the hierarchy (Wilcoxon matched pairs test: $\mathrm{T}=0.000000, \mathrm{n}=15$ dyads, $P=0.001 ; \mathrm{X} \pm \mathrm{SD}_{\mathrm{up} \mathrm{hierarchy}}=0.1 \pm$ $0.001 \%$ of samples; $\mathrm{X} \pm \mathrm{SD}_{\text {down hierarchy }}=1.0 \pm 0.013 \%$ of samples). When aggressing against females lower-ranking than themselves, females were more frequently aggressive toward females with a smaller rank distance from themselves than toward females with a larger rank distance from themselves (Kendall: $\tau=$ $-0.739, \mathrm{n}=15$ dyads, $P=0.0001$ ). When aggressing against females higher ranking than themselves, there was no tendency for females to be more frequently aggressive to females with a smaller rank distance from themselves (Kendall: $\tau=$ $-0.235, \mathrm{n}=15$ dyads, $P=0.19$ ). Although lower-ranking females were more often the victim of aggression than higher-ranking females (Kendall: $\tau=0.788, n=6$ individuals, $P=0.03$ ), higher-ranking females did not engage in more frequent aggression than lower-ranking females (Kendall: $\tau=-0.358, \mathrm{n}=6, P=0.30$ ). Females received more frequent agonism from the female partners they groomed more $\left(K_{r}\right.$ test: $\left.K_{r}=24, P=0.02\right)$.

\section{Female-Female Coalitions}

In no case did two females form a coalition against a female who was higher ranking than both of them. In 43 of 45 cases, the victim was lower ranking than both coalition partners. In the two remaining cases, the victim was intermediate in rank between the two coalition partners. In both of these cases, an adult male also participated in the coalition, and in one case the female being targeted by the coalition was mating with an adult male.

Those adult female dyads that groomed more frequently also formed coalitions more often, both against females (Kendall: $\tau=0.557, \mathrm{n}=15$ dyads, $P=0.004 ; K_{r}$ test: $K_{r}=22, P_{r}=0.04$ ) and against males (Kendall: $\tau=0.468, \mathrm{n}=15$ dyads, 


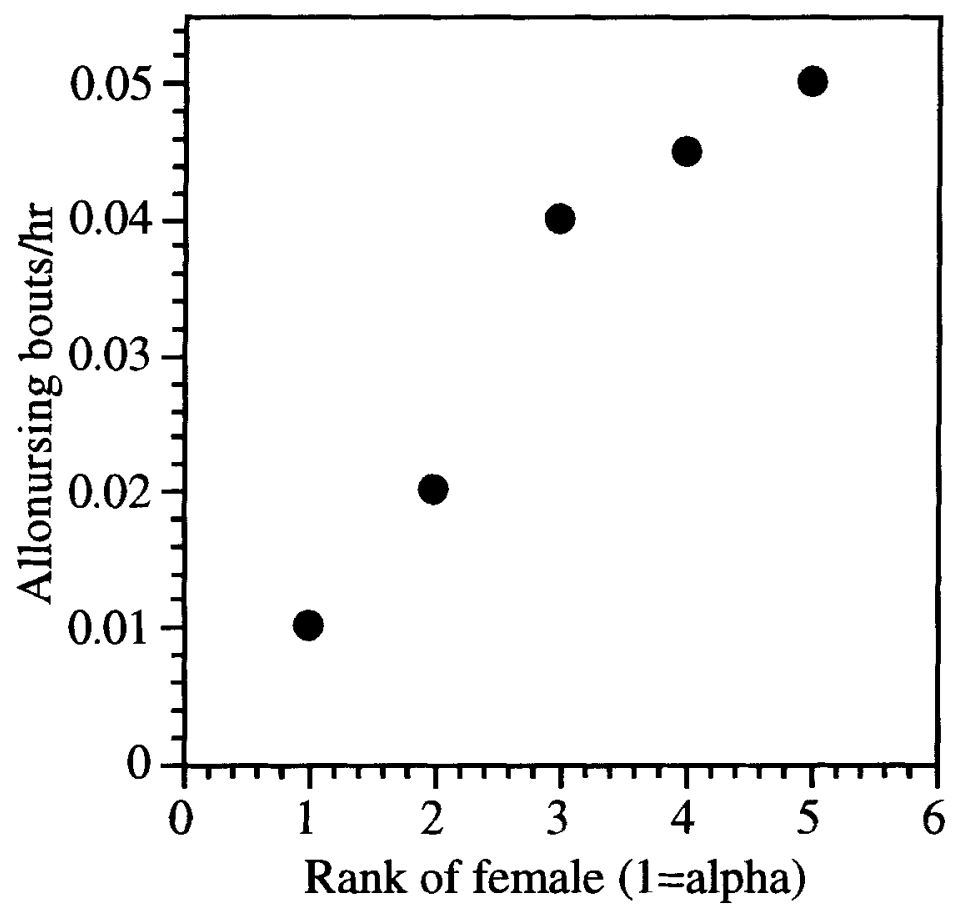

Fig, 2. Hourly rate at which females nurse infants other than their own, plotted against female rank.

$=0.015 ; K_{r}$ test: $\left.K_{r}=20, P_{r}<0.05\right)$. Males were far more frequent victims of female-female coalitions than were females. Figures 4 and 5 show the proportion of samples in which coalitions occurred, plotted against grooming rates, for female-female coalitions against females and males, respectively. When rank was held constant (using mean ranks of dyads for the Kendall rank correlation tests), there was still a significant correlation between grooming rate and proportion of samples involving coalitions against female victims $(\tau=0.481, \mathrm{n}=15$ dyads, $P<$ $0.02 ; K_{r}$ test: $\tau_{\mathrm{Krxy.z}}=0.351, P_{r}<0.05$ ), but not between grooming rate and proportion of samples including coalitions against male victims $(\tau=0.374, \mathrm{n}=15$ dyads, $P<0.1 ; K_{r}$ test: $\left.\tau_{\text {Krxy.z }}=0.304, P_{r}<0.1\right)$. The correlation between average rank of the coalition dyad and proportion of samples including coalition formation was highly significant for coalitions against both adult male victims $(\tau=-0.778$, $\mathrm{n}=15$ dyads, $P=0.00005)$ and adult female victims $(\tau=-0.555, P=0.004)$.

I used Hemelrijk's [1990b] methods to test whether there might be an exchange of grooming for agonistic support against males and females, respectively. There were nonsignificant tendencies for females to more frequently groom those females who supported them against females $\left(K_{r}\right.$ test: $\left.K_{r}=13, P_{r}<0.1\right)$ and against males $\left(K_{r}=15, P_{r}=0.1\right)$. Both effects disappeared entirely when rank was partialled out (for support against females: $\tau_{\text {Krxy.z }}=0.194, P=0.2$; for support against males: $\tau_{\text {Krxy.z }}=0.006, P=0.6$ ). Diablita, the youngest female who was in the process of working her way into the adult dominance hierarchy, received a disproportionate amount of support against females from higher-ranking adult females. Female rank was only weakly positively correlated with tendency to 


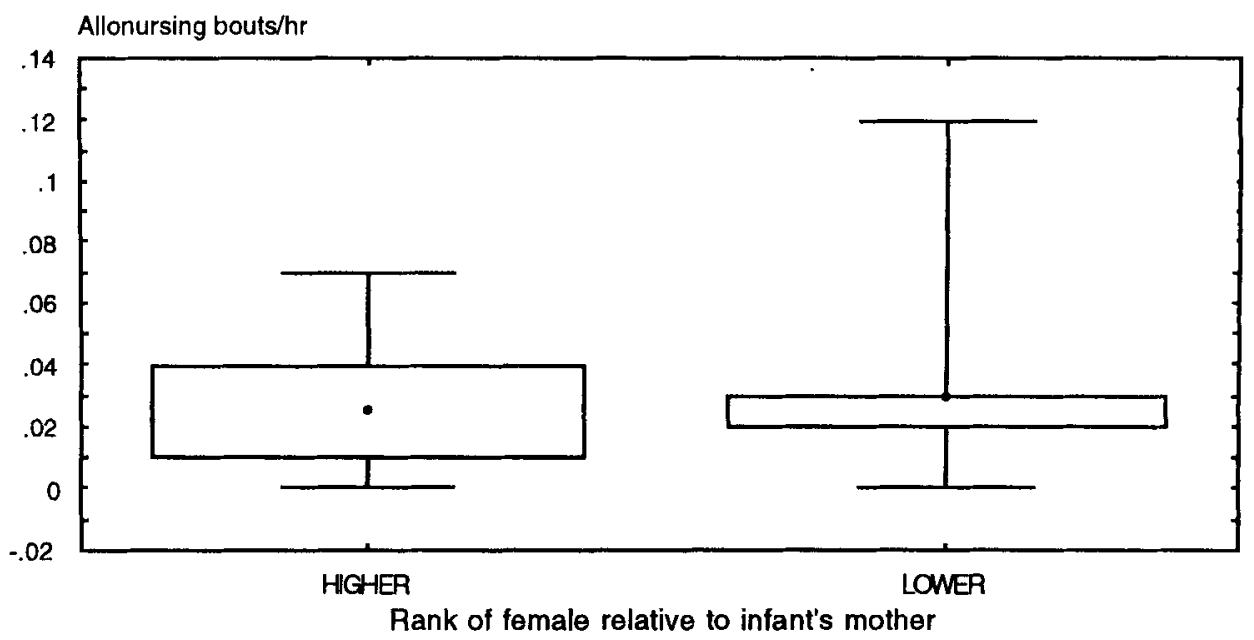

Fig. 3. Rates at which infants allonurse from females higher ranking and lower ranking than their own mothers. Boxes show the median and interquartile range, and whiskers show the total range of variation.
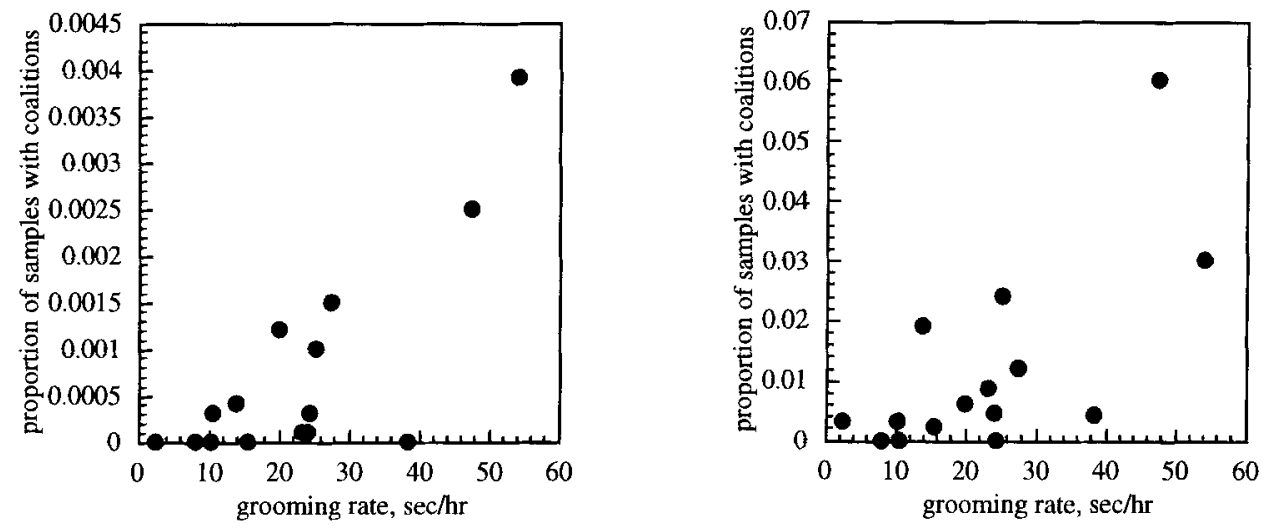

Fig. 4. Proportion of samples including coalitions against females, plotted against grooming rates; each data point is a dyad's score.

Fig. 5. Proportion of samples including coalitions against males, plotted against dyadic grooming rates; each data point is a dyad's score.

support females against females $\left(K_{r}\right.$ test: $\left.K_{r}=17, P_{r}=0.07\right)$. However, higherranking females were significantly more likely than lower-ranking females to support females against males $\left(K_{r}=37, P_{r}=0.0055\right)$. Some female-female dyads-most notably, the dyad consisting of Abby (the alpha female) and Squint (the beta female), which was responsible for $38 \%$ of all female-female coalitions formed vs. females-were highly consistent in their support of one another and formed coalitions against females at high rates. Five female-female dyads were never observed to form coalitions against females.

Of the 36 female-female coalitions against females, $12(33 \%)$ were classified as 


\section{8 / Perry}

"unprovoked": that is, they occurred when the females (coalition partners and victim) had not been foraging or socializing with one another. The fact that these unprovoked conflicts occurred disproportionately among adjacently ranked dyads including young females (i.e., females who had recently acquired their rank) indicates that these conflicts may have served to reinforce dominance relationships. An additional nine female-female coalitions against females $(25 \%)$ occurred in the context of feeding competition, and the remaining coalitions occurred in a variety of social contexts such as intervention in fights, redirected aggression, or disruption of affiliative interactions.

\section{DISCUSSION}

\section{Are White-Faced Capuchins Female Bonded?}

Data on six females of a single social group cannot be regarded as necessarily representative of the social patterns of an entire species or even a population. However, several lines of evidence indicate that white-faced capuchins studied at Lomas Barbudal are female bonded-i.e., that females maintain long-term, differentiated, affiliative relationships with other females based on grooming, close proximity, dominance interactions, and coalitionary aid [Wrangham, 1980]. Female-female dyads, relative to female-male or male-male dyads, spent more time in proximity. Females groomed one another approximately 55 times as often as males groomed one another. In my study, females supported one another frequently against males, whereas males never supported one another against females [Perry, 1995]. Female-female relationships were relatively stable throughout the study, whereas male-male and male-female relationships changed dramatically over the course of the study [Perry, 1995]. Female relationships were highly differentiated; for instance, some females consistently supported one another against other females. Dominance rank was a good predictor of patterns of coalitionary aid. The above observations are largely consistent with Fedigan's [1993] observations of C. capucinus at Santa Rosa National Park, Costa Rica: in Fedigan's study of two capuchin groups, females interacted with females at higher rates than males interacted with males or males interacted with females. Females spent more time in proximity and engaged in higher rates of affiliation with females than males did with either males or females. Females formed a stable dominance hierarchy [Fedigan, 1993].

\section{Grooming Patterns}

Dunbar [1991, 1993] has argued that grooming in platyrrhine primates serves a primarily hygienic function, because body size explains more interspecific variance in grooming rates than does group size in platyrrhines, relative to catarrhines. Data from my study, as well as from O'Brien's [1993] study, suggest that grooming serves a social function in capuchins, as in catarrhine primates. My findings that (1) grooming rates are correlated, across dyads, with rates of agonism received, (2) grooming rate varies as a function of the relative rank distance between females and tends to be directed up the hierarchy, and (3) grooming rates vary as a function of a female's infant's age are difficult to reconcile with the notion that grooming serves a purely hygienic function. Also, although there does not appear to be a direct interchange of grooming for support, those dyads that groom the most also form coalitions most often. Thus, as argued by Snowdon [1993], Dunbar's [1993] exclusion of platyrrhines from his analysis of the relationships among group size, grooming rate, and neocortex size in primates is unjustified, at least for the genus Cebus. It remains a possibility that grooming does not serve the 
same "social glue" function in other platyrrhines [Dunbar, 1991; Glezer \& Kinzey, 1993].

Furthermore, the data presented here provide marginal support for Seyfarth's [1977] model of grooming and competition for grooming partners in female-bonded monkeys. His model includes the following features: (1) All females compete for the opportunity to interact with high-ranking females, who are the most valuable coalition partners. Thus, high-ranking females receive more grooming than they direct, and grooming rates are disproportionately high among females with adjacent ranks. (2) Females preferentially groom with kin. The relative effects of kinship and rank on grooming decisions vary across groups and species. (3) Young infants are attractive to females; thus, females with new infants receive more grooming than do females without young infants. Among my subjects, grooming was directed up the dominance hierarchy; this result was statistically significant when tested with the $K_{r}$ test, but nonsignificant using a Wilcoxon test. As predicted by the Seyfarth model, those dyads with smaller rank distances groomed more often. Kinship relationships of the adult females in my study group are unknown; therefore I could not assess the effects of kinship on grooming preferences. The limited data available suggest that females with new infants were groomed more than females without new infants. My results do not support the hypothesis that females groom higher-ranking females because they are the most valuable coalition partners, because comparision of grooming and support matrices indicated that there was no interchange of grooming for coalitionary support (at least when rank was controlled for). However, Noë et al. [1991] have argued that, because individuals vary in their value as social partners and this variation affects their payoffs from exchange relationships, balanced exchanges of social favors are not necessarily expected on theoretical grounds.

In contrast to my findings, O'Brien [1993] found that female wedge-capped capuchins, $C$. olivaceus, preferentially directed grooming down the dominance hierarchy. O'Brien interprets his results as signifying that grooming-at least, in dyads consisting of females with disparate ranks-serves an appeasement function: low-ranking females solicit grooming from approaching high-ranking females as a way of diverting high- rankers from attacking them. Grooming in O'Brien's [1993] study was not more frequent among adjacently ranked females, despite the fact that adult females of adjacent rank were more consistently nearest neighbors [O'Brien \& Robinson, 1993].

\section{Allomothering}

Among my subjects, lower-ranking females engaged in more allonursing than did higher-ranking females, but the ranks of infants' mothers were not consistently higher than the allonursing females' ranks. These results differ from observations by O'Brien [1988] and O'Brien and Robinson [1991] of C. olivaceus, suggesting that allonursing by juveniles was parasitic and that allonursing by infants was unrelated to kinship or rank.

Because $C$. capucinus infants are often widely separated from their foraging mothers, even in the first few months of life, it is often difficult for infants to locate their mothers when they need to nurse. Therefore, there could be a great advantage to infants in being able to nurse from the closest lactating female. Even if not all females engaged in allonursing at equal rates, allonursing could be an evolutionarily stable strategy because the cost of giving a small amount of milk to a distantly related infant may be small compared to the benefit to a mother of her infant receiving the same amount of milk from an allomother while the mother is 
separated from the group for such a long period of time that the infant could become dehydrated or starve without milk. Once, during the pilot study in 1990, Wiggy became separated from the group for 2-5 days, and her 2.5-month-old infant Juege would almost certainly have died, had he not received milk from allomothers. Cheaters could be detected and discriminated against if infants threw noisy tantrums when denied milk by allomothers (which they sometimes do).

\section{Advantages to Being High Ranking}

Costs and benefits of social life were not equally distributed among females in this study, and they tended to vary according to rank. Aggression was 10 times more likely to be directed down the hierarchy as up the hierarchy, and lowerranking females were more often the recipients of aggression than were higherranking females. Therefore, it is possible that low-ranking females incurred more costs than high-ranking females, due to wounding, stress, and possibly reproductive suppression (though the limited demographic data available from my site do not indicate that low-rankers had longer interbirth intervals than high-rankers). Supplants at feeding sites were directed down the hierarchy 42 times as often as they were directed up the hierarchy, so it is possible that low-rankers had inferior access to preferred food sources. The four top-ranked females tended to be surrounded by other monkeys, whereas the two lowest-ranking females were more isolated on the periphery of the group. Therefore, low-ranking females may be more vulnerable to predation. Indeed, the lowest-ranking and most peripheral female of the group (Tattle) lost two of her three infants due to unknown causes, whereas only one of the other females lost an infant during the study, and that infant appeared to have died of an umbilical hernia rather than predation. Higherranking females bore less of the cost of allonursing than did lower-rankers, although they appeared to receive approximately equal benefits. There was a tendency for females to groom up the hierarchy rather than down, indicating that higher-ranking females may receive more of the benefits of grooming than do lower-ranking females. Higher-ranking females both gave and received coalitionary aid significantly more often than did lower-ranking females.

\section{Implications for Socioecological Models of Female-Female Relationships}

Models of primate social organization [e.g., Wrangham, 1980; van Schaik, 1989], which should apply equally well across the order, have relied almost entirely on data and assumptions derived from studies of catarrhines. Expanding the available data set on primate social behavior to include more platyrrhines and prosimians provides a means to test the generality of these models [Strier, 1990]. Furthermore, our understanding of female-bonded primate societies [Wrangham, $1980]$ is based almost entirely on studies of an even narrower taxonomic group, the cercopithecine monkeys. Because female philopatry has been observed in only two platyrrhine taxa, Saimiri sciureus and Cebus [Robinson \& Janson, 1987], and because Saimiri and Cebus are throught to be sister taxa [Rosenberger, 1992], it is likely that female philopatry in Saimiri sciureus and Cebus evolved independently of its evolution in the cercopithecines. Therefore, similarities between these taxa in female social behavior are likely to reflect general functional correlates of female philopatry in primates rather than effects of common ancestry. Differences between these taxa in female social behavior will be more difficult to interpret. One possible difference between the cercopithecines and Cebus is the role of kinship in determining the pattern of female-female interactions. In C. olivaceus, only the alpha female regularly aids her own offspring in rank acquisition [O'Brien \& 
Robinson, 1993], whereas female macaques of all ranks aid kin in acquiring a place in the dominance hierarchy just below the mother's rank [Chapais, 1992]. Although kinship relationships among my subjects were not known, my data indicate that the alpha female is not the only female who aids adolescent females in acquiring rank in C. capucinus.

Wrangham's [1980] and van Schaik's [1989] models focused on the effects of food distribution and feeding competition, neither of which were measured rigorously in this study, on the patterning of social relationships. However, I was able to test contrasting predictions generated by the models regarding female participation in intergroup aggression. In contrast with Wrangham's [1980] model, but consistent with van Schaik's [1989] model, females of my study group rarely participated in intergroup aggression [Perry, in press].

\section{CONCLUSIONS}

1. Female white-faced capuchin monkeys spent much more time in proximity with other females than they did with males; female-female and male-female dyads spent much more time in proximity than did male-male dyads.

2. Females had a stable, linear dominance hierarchy as determined by the direction of dyadic cowering and avoidance.

3. Females tended to groom females higher ranking than themselves, and dyads with smaller rank distances groomed more than dyads with larger rank distances.

4. All females allonursed. Rate of allonursing was positively, linearly related to dominance rank such that lower-ranking females allonursed more frequently than higher-ranking females, but the rank of the infant's mother relative to the allomother did not influence rates of dyadic allonursing.

5. Coalitionary aggression was directed primarily down the female hierarchy: in no case did two females form a coalition against a female higher-ranking than both of them, and females very rarely formed coalitions against females intermediate in rank between the coalition partners. Adult males were the most common victims of female-female coalitions.

6. Although those dyads that groomed most frequently also formed coalitions most frequently, there was no statistically significant association between grooming and support when rank was partialled out.

\section{ACKNOWLEDGMENTS}

This research was funded by the National Geographic Society, two grants from the Leakey Foundation, an NSF graduate fellowship, Sigma Xi, the University of Michigan Alumnae Society, a Rackham Research Partnership grant (with B. Smuts), a Rackham predoctoral fellowship, a Rackham dissertation grant, NSF awards (to B. Smuts and J. Mitani), and the Evolution and Human Behavior Program. J. Manson, J. Gros-Louis, and L. Sirot aided in data collection. L. Sirot, M. Tomaszycki, M. Landys, and S. Newman helped transcribe and computerize the data. J. Manson, B. Smuts, J. Mitani, W. Holmes, J. Pepper, B. Low, and four anonymous reviewers commented on the manuscript, and the graduate students in the EHB Program provided many stimulating discussions. C. Hemelrijk kindly allowed me to use her statistical software. G. Frankie, J. Frankie, K. Glander, M. Cedillos, and S. Rosales provided logistical assistance in the field. The Costa Rican Servicio de Parques Naciónales and the Area de Conservación Tempisque granted permission to work in Lomas Barbudal Biological Reserve. L. Fedigan allowed me to cite some of her unpublished observations. 


\section{REFERENCES}

Appleby, M.C. The probability of linearity in hierarchies. ANIMAL BEHAVIOUR 31: 600-608, 1983.

Chapais, B. The role of alliances in social inheritance of rank among female primates. Pp. 29-60 in COALITIONS AND ALLIANCES IN HUMANS AND OTHER ANIMALS. A.H. Harcourt; F.B.M. de Waal, eds. Oxford, Oxford University Press, 1992.

Dunbar, R.I.M. Functional significance of social grooming in primates. FOLIA PRIMATOLOGICA 57:121-131, 1991.

Dunbar, R.I.M. Coevolution of neocortical size, group size and language in humans. BEHAVIORAL AND BRAIN SCIENCES 16:681-735, 1993.

Fedigan, L.M. Sex differences and intersexual relations in adult white-faced capuchins (Cebus capucinus). INTERNATIONAL JOURNAL OF PRIMATOLOGY 14: 853-877, 1993.

Frankie, G.W.; Vinston, S.B.; Newstrom, L.E.; Barthell, J.F. Nest site and habitat preferences of Centris bees in the Costa Rican dry forest. BIOTROPICA 20:301-310, 1988.

Glezer, I.I.; Kinzey, W.G. Do gossip and lack of grooming make us human? BEHAVIORAL AND BRAIN SCIENCES 16:704$705,1993$.

Hemelrijk, C.K. Models of, and tests for, reciprocity, unidirectionality and other social interaction patterns at a group level. ANIMAL BEHAVIOUR 39:1013-1029, 1990a.

Hemelrijk, C.K. A matrix partial correlation test used in investigations of reciprocity and other social interaction patterns at group level. JOURNAL OF THEORETICAL BIOLOGY 143:405-420, 1990b.

Kendall, M.G. RANK CORRELATION METHODS. London, Charles Griffin, 1962. Noë, R.; van Schaik, C.P.; van Hooff, J.A.R.A.M. The market effect: An explanation for pay-off asymmetries among collaborating animals. ETHOLOGY 87:97-118, 1991.

O'Brien, T.G. Parasitic nursing behavior in the wedge-capped capuchin monkey (Cebus olivaceus). AMERICAN JOURNAL OF PRIMATOLOGY 16:341-344, 1988.

O'Brien, T.G. Allogrooming behaviour among adult female wedge-capped capuchin monkeys. ANIMAL BEHAVIOUR 46: 499-510, 1993.

O’Brien, T.G.; Robinson, J.G. Allomaternal care by female wedge-capped capuchin monkeys: Effects of age, rank and relatedness. BEHAVIOUR 119:30-50, 1991.

O'Brien, T.G.; Robinson, J.G. Stability of social relationships in female wedge-capped capuchin monkeys. Pp. 197-210 in JUVENILE PRIMATES. M. Pereira; L. Fairbanks, eds. Oxford, Oxford University Press, 1993.

Oppenheimer, J.R. Social and communicatory behavior in the Cebus monkey. Pp. 251-271 in BEHAVIORAL REGULATORS OF BEHAVIOR IN PRIMATES. C.R. Carpenter, ed. Cranbury, NJ, Associated University Presses, 1973.

Oppenheimer, J.R.; Oppenheimer, E.C. Preliminary observations of Cebus nigrivittatus (Primates: Cebidae) on the Venezuelan Llanos. FOLIA PRIMATOLOGICA 19: 409-436, 1973 .

Perry, S. Social relationships in wild whitefaced capuchin monkeys, Cebus capucinus. Ph.D. dissertation, University of Michigan-Ann Arbor, 1995.

Perry, S. Intergroup encounters in wild white-faced capuchins, Cebus capucinus. INTERNATIONAL JOURNAL OF PRIMATOLOGY, 17:000-000, 1996.

Robinson, J.G.; Janson, C.H. Capuchins, squirrel monkeys, and Atelines: Socioecological convergence with Old World primates. Pp. 69-82 in PRIMATE SOCIETIES. B.B. Smuts; D.L. Cheney; R.M. Seyfarth; R.W. Wrangham; T.T. Struhsaker, eds. Chicago, University of Chicago Press, 1987.

Rosenberger, A.L. Evolution of New World monkeys. Pp. 209-216 in THE CAMBRIDGE ENCYCLOPEDIA OF HUMAN EVOLUTION. S. Jones; R. Martin; D. Pilbeam, eds. Cambridge, Cambridge University Press, 1992.

Seyfarth, R.M. A model of social grooming among adult female monkeys. JOURNAL OF THEORETICAL BIOLOGY 65:671698, 1977.

Snowdon, C.T. The rest of the story: Grooming, group size and vocal exchanges in neotropical primates. BEHAVIORAL AND BRAIN SCIENCES 16:718, 1993.

Strier, K.B. New World primates, new frontiers: Insights from the woolly spider monkey, or muriqui (Brachyteles arachnoides). INTERNTIONAL JOURNAL OF PRIMATOLOGY 11:7-19, 1990.

van Schaik, C.P. The ecology of social relationships amongst female primates. $P p$. 195-218 in COMPARATIVE SOCIOECOLOGY, THE BEHAVIOURAL ECOLOGY OF HUMANS AND OTHER MAMMALS. V. Standen; G.R.A. Foley, eds. Oxford, Blackwell, 1989.

Wrangham, R.W. An ecological model of female-bonded primate groups. BEHAVIOUR 75:264-300, 1980. 